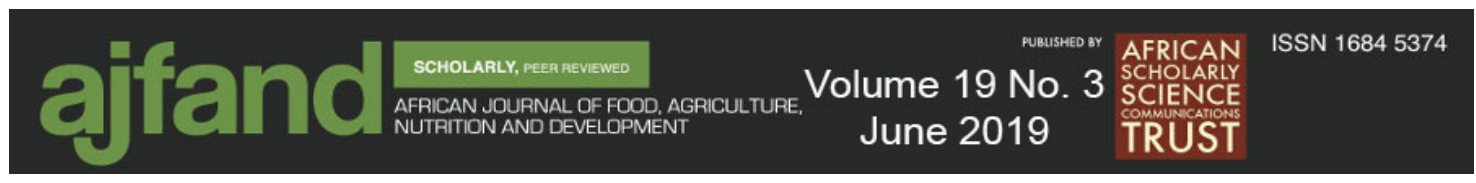

Afr. J. Food Agric. Nutr. Dev. 2019; 19(3): 14571-14586

DOI: 10.18697/ajfand.86.17745

\title{
DETERMINANTS OF ADOPTION AND USE-INTENSITY OF SOIL AND WATER CONSERVATION PRACTICES AMONG SMALLHOLDER \\ FARMERS IN NIGERIA
}

\section{Olawuyi SO ${ }^{1^{*}}$ and A Mushunje ${ }^{1}$}

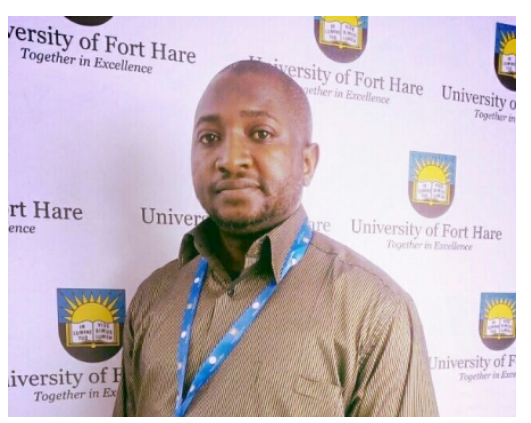

Dr. Olawuyi, Seyi Olalekan

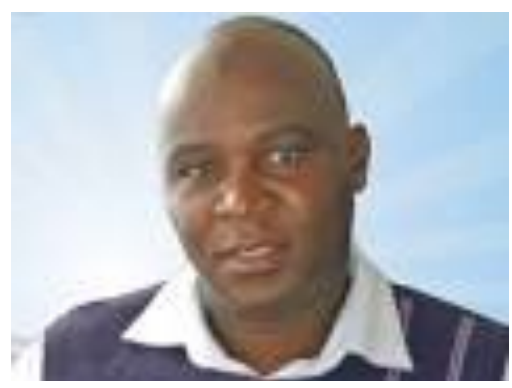

Prof. Mushunje, Abbyssinia

*Corresponding author's e-mail: seyidolapo1704@gmail.com

${ }^{1}$ Department of Agricultural Economics and Extension, University of Fort Hare, P/Bag X1314, Alice 5700, Eastern Cape Province, South Africa 


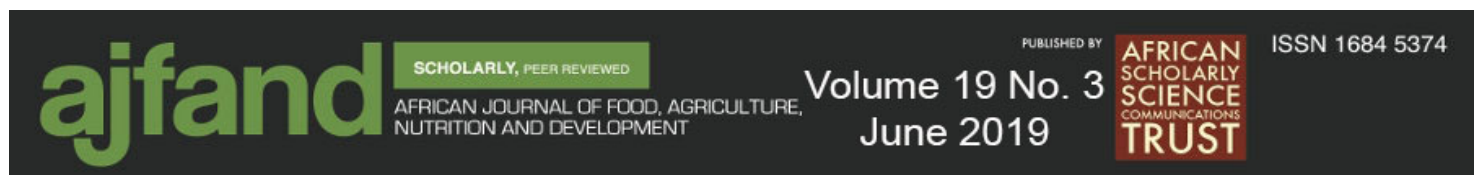

\begin{abstract}
Smallholder farmers are faced with myriads of soil and water related issues in production, which makes them vulnerable to land degradation and low productivity. Land resource degradation remains a major threat to food security leading to persistent poverty among the agrarian and urban populace. Therefore, there is need for appropriate interventions such as improved soil and ground water conservation (SWC) practice. This study examined the dynamics influencing the use and extent of use of SWC practices among smallholder farmers in Nigeria with particular reference to Osun State. The sampling technique used involved random selection in many stages to select the representative sample of 240 respondents. Data collected through primary source included: farmers' socio-economic attributes, farm level characteristics as well as the use of SWC practices in the study area. The data were analyzed using descriptive statistics, binary probit and negative binomial regression models. Findings from the count of SWC practices revealed that on the average, most farmers use at least one SWC practice. The results also indicated that fairly aged farmers were the set of people in the study area who adopted between 2 to 3 different SWC practices. Estimation of binary probit and its marginal effects at the means (MEMs) revealed that age of the farmers $(p<0.01)$, gender $(p<0.01)$, years of formal education $(p<0.01)$ and farm size under cultivation $(p<0.1)$ were significant determinants of SWC practices adoption. Similarly, the count model estimates revealed that age of the farmer $(p<0.01)$, gender $(p<0.01)$ and the size of farmland put under cultivation $(p<0.05)$ significantly determined the log counts of SWC practices adopted by smallholder farmers in the study area. However, the test of overdispersion parameter showed that the model fits well. Therefore, there is need for massive campaign by the institutional establishments saddled with agricultural development policies on the need for SWC farming practices, so that the resource-poor farmers can have remunerative livelihoods in Nigeria.
\end{abstract}

Key words: Adoption, binary probit, conservation, negative binomial model, smallholders, Nigeria 


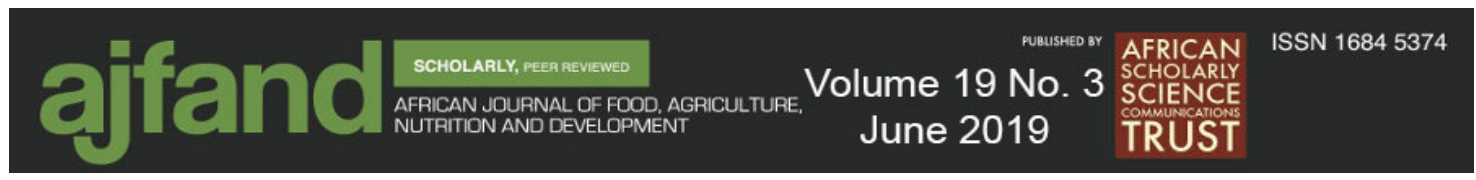

\section{INTRODUCTION}

The need for sustainable soil and water conservation (SWC) practices in farming activities has been at the forefront and remains a top priority of policy debates among agricultural researchers, government agencies and development stakeholders. Soil degradation and depletion as a result of natural occurrence, and human-induced factors have significantly affected crop output among resource-poor farmers in sub-Saharan African countries and Nigeria in particular; hence, the need to be pro-active in mitigating this environmental problem associated with agricultural production. In line with this objective, Ezeaku noted that good and efficient combination of SWC practices could sustainably guard against soil depletion and ground water loss [1]. Importantly, soil and ground water management practices efforts offer and promote minimum disturbance of the soil by tillage (minimum tillage) as well as balanced application of chemical inputs which are required to improve soil quality for healthy crop production [2]. Further, the authors noted that effective SWC practices can potentially boost soil productivity, reduce long-term dependency on external inputs which often times lead to increased cost of production and enhance environmental management as well as reduce emission of greenhouse gases from human activities such as burning. All else equal, achieving these in Nigeria suggests that increased productivity, safe environment, less cost of production and increased farmers' income are assured.

Similarly, Nyangena opined that land resource degradation remains a significant threat to food crisis and persistent poverty among the populace especially the agrarian ones [3]. Unsustainable land management practices have adverse effects on the agricultural production due to gradual loss in capacity of the soil to sustain crop yields. There is evidence that crop yields are declining day by day; these are directly connected to soil erosion health and human activities $[4,5]$. The resultant effect is manifested in decreased ground water retention and loss of soil nutrients, with devastating effects on food and nutrition security as well as well-being of many farmers in Nigeria. Majority of the households in rural areas in Nigeria engage in farming activities for family sustenance and to earn meager income from the sales of their agricultural produce because of subsistence nature of their farming activities [6]. Suffice it to say that smallholder farmers constitute the bulk of farm families in Nigeria.

The fact that sustainable SWC practices are substantial means of promoting agricultural production, especially in the cultivation of food and export crops by farmers shows that there is the need for urgent policy intervention and genuine implementation in this direction. This requires focusing more attention on the contemporary issues and institutional factors that may have impact on the use and the use intensity of these SWC practices. Therefore, sustainability of SWC practices is important towards enhancing food crop production and preserving natural resources as well as a safe environment simultaneously. However, sustainability in this case involves "meeting the needs of the present without compromising the ability of future generations to meet their own needs" [7]. In light of this, the study investigated conservation efforts by smallholder farmers in Osun State, Nigeria to isolate the factors influencing their decisions to adopt conservation farming practices and the extent of use of these practices using the count model approach. 


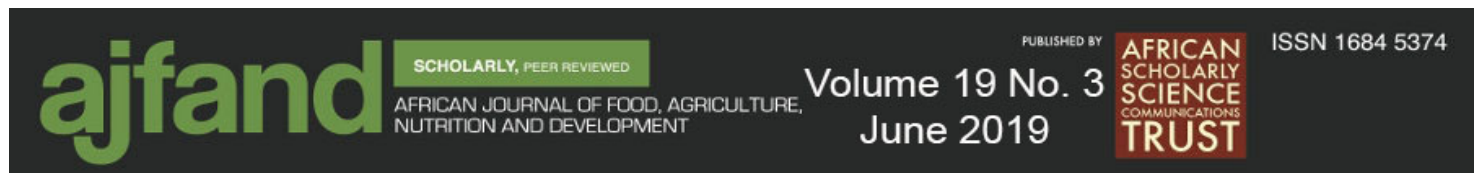

\section{MATERIALS AND METHODS}

\section{The Study Area}

This research was carried out in Osun State, south-west of Nigeria. The area is agrarian with a sandy loamy soil structure. This is responsible for the prevalent farming and farming related activities, which is mostly dominated by smallholder farmers. The prevalent staple food crops in the study area included: maize, cassava yam, cowpea, melon, vegetables as well as tree crops such as orange, mango and cashew to mention few.

More so, other livelihood activities prevalent in this area include but are not limited to food processing, marketing, and civil service, as well as trading activities. Similarly, there is a moderate level of social capital among the inhabitants of this area under study. Perhaps, this informed the observed interactions and homogeneity in culture, values and norms among the residents in the study area.

\section{Sampling Units and Procedure}

The Agricultural Development Programme (ADP) of Osun state is structured into 3 strata, which are: Osogbo, Iwo and Ife-Ijesha zones. Multistage random selection approach was adopted in selecting the sample size used for this study. A purposive selection of Iwo and Ife-Ijesha zones was carried out in the first stage, because of the prevalent agricultural activities in these zones. Thereafter, random sampling of 2 Local Government Areas (LGAs) from the chosen ADPzones was implemented in the second stage. In the third stage, random selection of 2 villages from each of the 4 LGAs selected in the second stage was carried out. Hence, a total of 8 villages were sampled. The last stage involved simultaneous use of proportionate to size and simple random sampling techniques to select 240 respondents used as sample size for this study. The proportionality factor formula expressed in equation one was applied across all the sampled respondents in all the selected villages.

$$
S=\frac{n}{N} \times 240
$$

Where:

$\mathrm{S}=$ sampled respondents from each of the selected villages,

$\mathrm{n}=$ population of registered farming households in each of the selected villages,

$\mathrm{N}=$ total population of registered farming households in all the 8 villages chosen,

$240=$ total number of respondents sampled in the study area.

It is worthy of note that data from only 221 respondents were used in the final analyses due to some incomplete responses.

\section{Data Collection and Analytical Techniques}

A well-structured questionnaire administered through oral interview was used to elicit the necessary information from the respondents. Some of the basic data obtained included: farmers and farm-based characteristics as well as the use of SWC practices by smallholder farmers in the study area. 


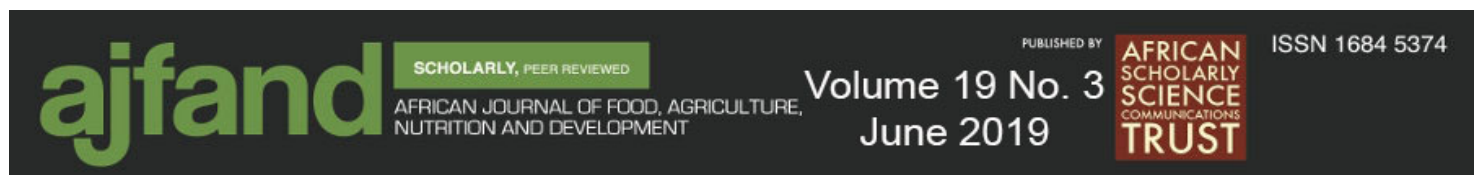

Frequency distribution, percentages, mean values, and cross-tabulation analytical techniques were used to describe the counts of SWC practices as adopted among the smallholder farmers in the study area. Binary probit regression model was used to isolate the determinants of adoption of SWC practices, while negative binomial distribution model and incidence rate ratio were used to mirror the use intensity of SWC practices in the study area.

\section{Binary Probit Regression Model Specification}

Binary probit regression is usually applied to model dichotomous or binary outcome variables. According to Long and Freese, regression models for dichotomous outcomes estimate the pattern of effect of explanatory variable(s) on the probability of occurrence of an event [8]. However, because of the non-linearity of this model, the levels of the explanatory variables involved determine the degree of change in the outcome probability that is associated with a given change in one of the explanatory variables. Following the estimation procedures of Long and Freese, as well as Williams, binary probit regression and marginal effects at the means (MEMs)estimation techniques were used to model the drivers of SWC adoption, the predicted probabilities, and partial effects of the hypothesized variables $[8,9]$. Importantly, based on Nagler's submission, probit model has the ability to include believable error term distribution as well as realistic probabilities [10]. Meanwhile, probit model assumes that while 0 and 1 values are only observed for the response variable $\mathrm{Y}$, there is a latent, unobserved continuous variable $\mathrm{Y}^{*}$ that determines the value of the response variable $\mathrm{Y}[11]$.

Therefore, $\mathrm{Y}^{*}$ is assumed to be expressed as:

$Y^{*}=X^{1} \beta+\varepsilon$

where:

$\varepsilon \sim N(0,1)$.

Then, $\mathrm{Y}$ can be viewed as an indicator for whether this latent variable is positive, such that:

$\mathrm{Y}=1\left(\mathrm{Y}^{*}>0\right)$, that is, 1 if $Y^{*}>0$ i.e. $\left(\varepsilon<X^{1} \beta\right)$, 0, Otherwise, where:

$\mathrm{Y}=$ vector of the response variable (that is: 1 for SWC practice(s) adoption, 0, otherwise);

$\mathrm{X}=$ vector of explanatory variables;

$\beta=$ probit coefficients; $\mu_{\mathrm{i}}=$ random error term.

\section{Modeling Negative Binomial Distribution}

Negative binomial regression usually estimates the count frequency of an event when such has extra-Poisson deviance, which is otherwise referred to as over-dispersion. In essence, binomial deals with a non-negative count variable. In this model, the count variable is assumed to be generated by Poisson-like process, except for the issue of overdispersion where the variation is greater than that of a true Poisson.

Baum noted that the negative binomial distribution is a two-parameter distribution. For positive integer $n$, "it is the distribution of the number of failures that occur in a sequence of trials before $n$ successes have occurred, where the probability of success in each trial is $p$ [12]". The distribution is defined for any positive $n$. The negative binomial 


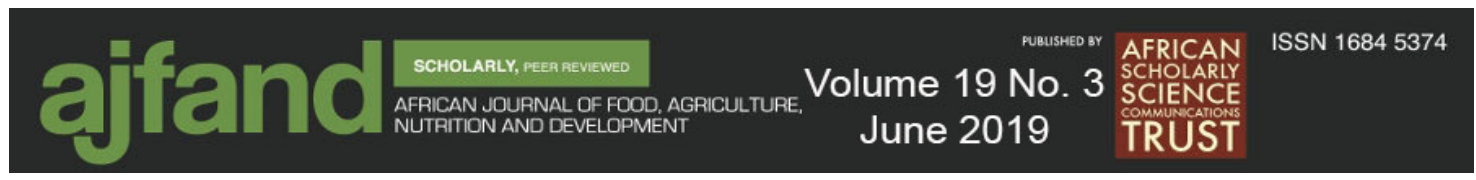

distribution combines both Poisson distribution and the Gamma distribution, or generalized factorial function [12]. Unlike the Poisson, which is fully characterized by its mean $\mu$, the negative binomial distribution is a function of both $\mu$ and $\alpha$. Its mean is still $\mu$, but its conditional variance is $\mu(1+\alpha \mu)$. Then, it is evident that as $\mu$ tends towards 0 (that is, $\mu \rightarrow 0$ ), the distribution becomes Poisson distribution.

The negative binomial distribution model with the following characteristics is expressed as:

$$
\operatorname{Pr}(Y=y \mid \lambda, \alpha)=\frac{\Gamma\left(y+\alpha^{-1}\right)}{y ! \Gamma\left(\alpha^{-1}\right)}\left(\frac{\alpha^{-1}}{\alpha^{-1}+\lambda}\right)^{\alpha^{-1}}\left(\frac{\lambda}{\alpha^{-1}+\lambda}\right)^{y}
$$

- The negative binomial distribution has two parameters; that is, $\lambda$ and $\alpha$

$-\lambda$ is the mean or expected value of the distribution

$-\alpha$ is the over dispersion parameter

- when $\alpha=0$, the negative binomial distribution is the same as a Poisson distribution.

However, to further show how the count variable changes with a unit change in individual covariates fitted in the model (while other covariates are held constant), incidence rate ratio of the negative binomial regression was also estimated.

\section{RESULTS AND DISCUSSION}

The results from the statistical analysis carried out on the data obtained from the respondents are discussed in detail. As revealed in Table 1, about half (57.5\%) of the respondents did not adopt any of the identified SWC practices in the study area. This suggested that most farmers are still practicing the old and traditional ways of farming. Consistent with findings by Olufunmilayo, Bamire and Ogunleye, this could be attributed to the observed prevalence of aged people in farming [13]. This was evidently shown in Table 2. In addition, farmers in these age categories were the set of individuals in the study area who adopted between 2 to 3 different SWC practices.

\section{Drivers of adoption of SWC practices in the study area}

The result shown in Table $3 \mathrm{~b}$ revealed that the probability of older farmers adopting SWC practices would be 1.7 percent points lower than for the younger ones. Similarly, the probability of male gender adopting SWC practices would be 41.1 percent points lower than for the female counterpart. However, the probability of farmers with many years of formal education to adopt SWC practices would be 2.4 percent points lower than those having no formal or few years of formal education. Similarly, the probability of adopting SWC practices would be 6 percent points lower for the farmers whose mode of land acquisition is through inheritance. This could be as a result of land fragmentation. The results further revealed that the probability of farmers with access to credit to adopt SWC practices would be 4.5 percent points lower than the others. Conversely, as expected, the probability of an average individual farmer with relatively large farmland size under cultivation to adopt SWC practices would be 5.5 percent point higher than those with small farmland size. This could be as a result of the spill-over effects of land fragmentation noted earlier. All these findings are partly in line with those reported by Awoyinka and Akinwumi [14]. 


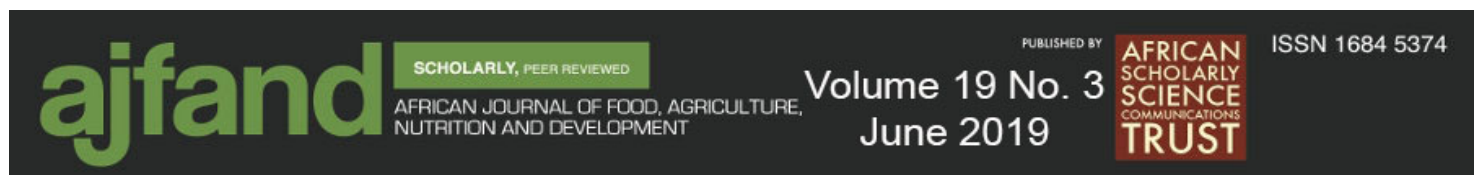

In the same vein, the results obtained from the marginal effects at the means (MEMs) with respect to discrete change for categorical variables in the fitted model as shown in Table $3 \mathrm{~b}$ also revealed that, for farmers with average values on age (53.97), years of formal education (6.86) and farmland size under cultivation (1.91), the predicted probability of adopting SWC practices is 0.41 less for the male-gender than the female counterpart, 0.06 less for the farmers whose mode of farmland acquisition is through inheritance than otherwise, and 0.04 less for farmers who did have access to credit compared to those without.

Generally, the findings revealed that age of the farmers $(p<0.01)$, gender $(p<0.01)$, years of formal education (a proxy for human capital) $(p<0.01)$ and farmland size under cultivation $(p<0.1)$ are significant drivers of soil and water conservation practices adoption in the study area.

It is important to note that the post-hoc test (that is, goodness of fit statistics measure) carried out to validate the model's goodness-of-fit clearly revealed that the model fits reasonably well (see: goodness-of-fit test 1).

However, the number of covariate patterns is close to the number of observations, making the applicability of the Pearson $\chi^{2}$ test questionable but not necessarily inappropriate. Therefore, to address this concern, Hosmer, Lemeshow and Sturdivant suggested regrouping the data by ordering the predicted probabilities, and then form 10 equal-sized groups [15]. This was applied and the estimates generated seemed better and reasonable, as indicated in Table 3c (goodness-of-fit test 2).

\section{Use Intensity of SWC practices: Count Model Estimates}

Considering the distribution of data, negative binomial distribution model is considered appropriate to estimate the count of SWC practices as adopted by farmers. More importantly, the incidence rate ratio (IRR) of the negative binomial regression model was also computed and reported as suggested by Piza to show the impact of explanatory variables in terms of a percentage change in the observed response variable (in this case, SWC practices adoption counts) [16]. In essence, "the IRR represents the change in the response variable in terms of a percentage change, with the precise percentage determined by the amount the IRR is either above or below 1" [16].

In line with this approach, Table 4a results revealed the unsuitability of the Poisson distribution model with respect to the count of SWC practices adopted. The Pearson goodness-of- fit test results also indicated that the distribution of SWC practices adoption count significantly differed for a Poisson distribution as evidently revealed by the large value recorded for chi-square in the post-hoc test. In this instance, negative binomial regression model is appropriate.

Consequently, Table $4 \mathrm{~b}$ revealed the findings from the negative binomial regression model with the same fitted response variable and the hypothesized covariates as used in Table 4a.Since count regression techniques model the log of incident counts, the findings in Table $4 \mathrm{~b}$ revealed that for every one unit increase in the age value of a farmer, the $\log$ 


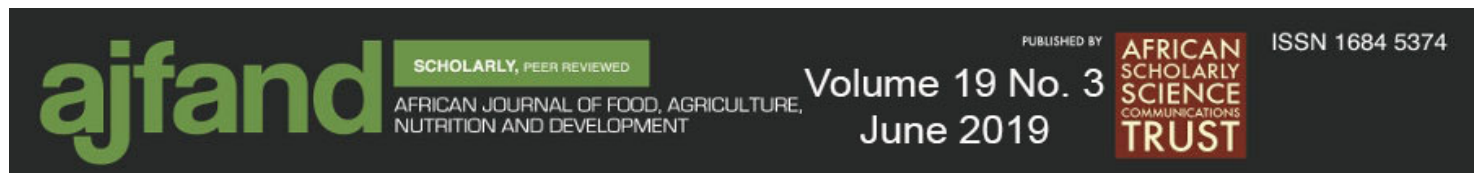

count of SWC practices adoption was expected to decrease by approximately 0.0272 with estimated statistical significance $p$-value of 0.000 which is below the standard threshold of $p<0.05$. This suggested that the finding is statistically significant. Similarly, it is evident from the result that male gender significantly $(p<0.01)$ adopted SWC practices less than the female counterpart. The implication of this is that for every unit increase in the value of male gender, the log count of SWC practices adoption is expected to decrease by approximately 0.724 . On the other hand, it was found that for every one unit increase in farmland size cultivated by the farmer, the $\log$ count of SWC practices adoption is expected to increase by approximately 0.2216 . This suggested that a unit increase in the farmland cultivated significantly $(p<0.05)$ increased the log count of SWC practices adopted by the farmer. In the same vein, the likelihood ratio test indicated in the negative binomial model analysis is a test of the over-dispersion parameter alpha. However, it is important to note that when the over-dispersion parameter tends to zero, the negative binomial distribution becomes the Poisson distribution equivalent. However, the results revealed that the alpha parameter was significantly different from zero, which reinforced the earlier submission that the Poisson regression model is not appropriate for the distribution of the counts data under consideration. This finding is consistent with what was reported by Pedzisa et al. [17].

The interpretation of results according to Piza is the more or less similar with count regression models types [16]. This means that the model parameters tend to communicate the same information in both Poisson and negative binomial regression models. The author further noted that reporting IRR can communicate more clearly and precisely the explanatory variable influence than the regression coefficient. Consequently, it is more tenable to report the incidence rate ratio (IRR) of the negative binomial regression model. Evidently, the process presented a better option of estimating the influence or effect of the explanatory variable(s) on the response variable than reporting regression coefficient arising from the Poisson or negative binomial models. This argument was also supported by Cameron and Trivedi [18].

The results as indicated in Table 4c indicated the IRR estimates of the negative binomial regression model. The results revealed that, if farmers' age were to increase by one point, the rate ratio for adoption of SWC practices would be expected to decrease by a factor of 0.97 or $97 \%$, given that other explanatory variables in the model are held constant. Equally, holding other explanatory variables in the model constant, male gender compared to female counterparts are expected to have a rate of 0.48 times lesser for adoption of SWC practices. Conversely, if a farmer were to increase the cultivated farm size by a unit, his rate for adoption of SWC practices would be expected to increase by a factor of 1.24 , while holding other explanatory variables constant.

To summarize, in line with a-priori expectations, age of the farmer $(p<0.01)$, gender $(p<0.01)$ and the size of farmland put under cultivation $(p<0.05)$ significantly determined the rate ratio for adoption incidence of SWC practices by smallholder farmers in the study area. 


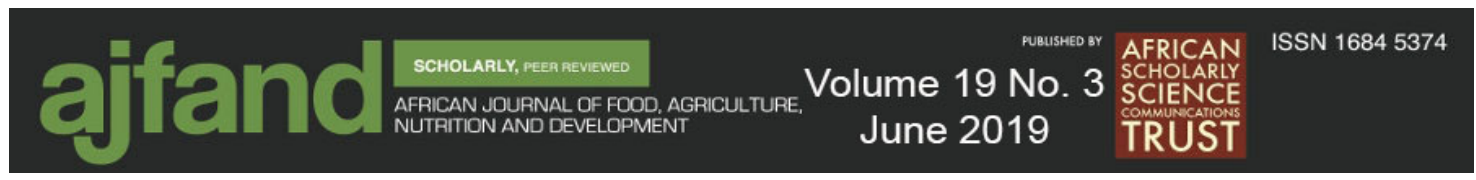

\section{CONCLUSION}

This study has established the need for farmers to adopt and scale up conservation efforts to achieve sustainable food production. However, the study revealed that on the average, farmers adopted at least one SWC practices in the study area and relatively older farmers constituted the category of individuals with positive adoption choice decision.

Importantly, farmers' personal characteristics (such as, age, gender, years of formal education) and farm level factors (for instance, farm size put to cultivation) significantly determined farmers' decisions to use and extend of use of SWC practices among the smallholder farmers in the study area.

The traditional land tenure system practices which lead to fragmentation of farmlands and by extension discourage adoption of SWC practices have also been identified as one of the major indirect setbacks for the improvement of agricultural productivity in Nigeria. The resultant effect is usually manifested in small output and meagre income. Ceteris paribus, access to sufficient farmland holding could translate into continued use of SWC practices, increased farm output and income.

Therefore, the following policy recommendations are important extracts from the study findings:

- Sensitization of youths on the need to participate in farming operations is of high necessity. This is because the findings revealed that fairly aged people are into farming compared to the young ones. Expectedly, it will aid easy uptake and scaling up of modern farming techniques.

- There is need for active participation of male gender in farming activities. Hence, agricultural policy in this direction should address the gender issue with respect to participation by males since males fair poorly against females in farming activities.

- Investment in human capital development is a pathway to achieve economic growth and development of any nation. As a result, there is a need to increase the budget share on education so that people can have access to basic education. Achieving this will facilitate adoption of modern agricultural technology such as SWC farming practices.

- Farmers' friendly policy in terms of guaranteed price support scheme (guaranteed minimum price) needs to be re-introduced to prevent malpractices in this sector to enable to sell their farm outputs in a more stable market condition even when there is a market glut. This will impact more directly on the demand and supply side of the market. Consequent to this, employment/job creation and reduction in social vices can equally be addressed.

\section{ETHICAL CONSIDERATIONS}

This study revealed the following ethical considerations: anonymity, informed consent, privacy, confidentiality as well as professionalism. Most importantly, the researchers hereby declare that there are no known associated risks attached to this study in the chosen study area.

In essence, this study did not have any ethical law restraints or tendency to breach human rights. 


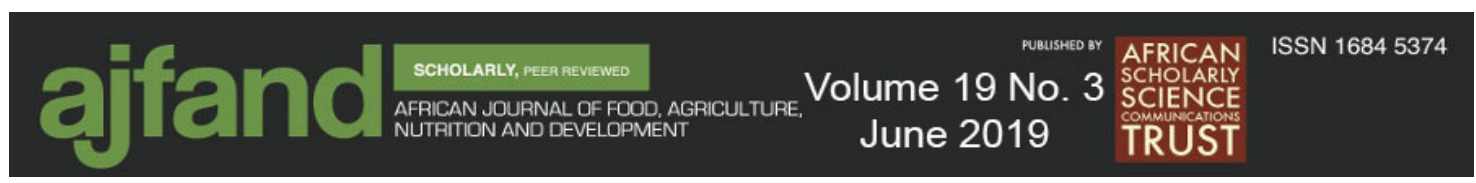

Table 1: Count of SWC practices adopted across the sampled respondents

\begin{tabular}{lc}
\hline Count of SWC practices adopted & Frequency \\
\hline 0 & $127(57.47)$ \\
1 & $13(5.88)$ \\
2 & $35(15.84)$ \\
3 & $36(16.29)$ \\
4 & $10(4.52)$ \\
Mean (1.045) & \\
Total & $\mathbf{2 2 1}(\mathbf{1 0 0 . 0})$ \\
\hline
\end{tabular}

Source: Data analysis, 2017

Figures in parentheses are percentage values

Table 2: Cross-tabulation: Respondents' age group and number of SWC practices adopted

\begin{tabular}{lcccccc}
\hline Age group (years) & None & One & Two & Three & Four & Total \\
\hline $20-30$ & 6 & 0 & 0 & 4 & 3 & $\mathbf{1 3}$ \\
$31-40$ & 11 & 1 & 4 & 2 & 2 & $\mathbf{2 0}$ \\
$41-50$ & 22 & 4 & 8 & 16 & 1 & $\mathbf{5 1}$ \\
$51-60$ & 29 & 3 & 14 & 10 & 3 & $\mathbf{5 9}$ \\
$61-70$ & 46 & 4 & 7 & 3 & 1 & $\mathbf{6 1}$ \\
$71-80$ & 13 & 1 & 2 & 1 & 0 & $\mathbf{1 7}$ \\
Mean (53.97) & & & & & & \\
Total & 127 & 13 & $\mathbf{3 5}$ & $\mathbf{3 6}$ & 10 & $\mathbf{2 2 1}$ \\
\hline
\end{tabular}

Source: Data analysis, 2017 


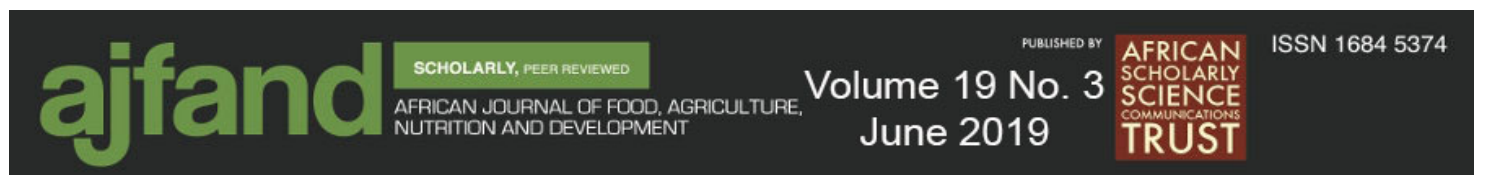

Table 3a: Binary Probit Estimates

\begin{tabular}{l|cccc}
\hline $\begin{array}{l}\text { SWC adoption } \\
\text { decision }\end{array}$ & coefficient & std. error & $\mathbf{z}$ & $\mathbf{p}>|\mathbf{z}|$ \\
\hline Constant & 4.5210 & 0.7762 & $5.82^{*}$ & 0.000 \\
age & -0.0477 & 0.0092 & $-5.14^{*}$ & 0.000 \\
1.gender & -1.5137 & 0.3593 & $-4.21^{*}$ & 0.000 \\
years of formal & -0.0649 & 0.0236 & $-2.75^{*}$ & 0.006 \\
education & -0.1650 & 0.2924 & -0.56 & 0.572 \\
1.land-acquisition & -0.1201 & 0.2189 & -0.55 & 0.583 \\
1.access-to-credit & 0.1472 & 0.0901 & $1.63^{* * *}$ & 0.103 \\
farm size cultivated & & & & \\
\hline
\end{tabular}

Number of observations $=221, \log$ likelihood $=-115.40541$

LR chi $^{2}(6)=69.34$, Prob $>$ chi $^{2}=0.0000$, Pseudo $\mathrm{R}^{2}=0.2310$

${ }^{*} p<0.0 ; * * * p<0.1$ level, respectively

Source: Data analysis, 2017

\section{Marginal Effects at the Means (MEMs) Estimates of Binary Probit Model}

The estimate as obtained from the marginal effects at the means after binary probit regression is presented as follows:

Conditional marginal effects $\quad$ Number of obs $=221$

Model VCE: OIM

Expression: Pr (SWC adoption decision), predict ()

dy/dx w.r.t.: age, 1. gender, years spent in school, 1. land acquisition, 1. access to credit, farm-size under cultivation

$\begin{array}{lll}\text { at: age } & = & 53.96833 \text { (mean) } \\ 0 . \text { gender } & =0.1719457 \text { (mean) } \\ 1 . \text { gender } & =0.8280543 \text { (mean) } \\ \text { yrssptschl } & =6.855204 \text { (mean) } \\ 0.1 \text { landacq } & =0.1538462 \text { (mean) } \\ 1 . \text { landacq } & =0.8461538 \text { (mean) } \\ 0 . \text { accredt }= & 0.6606335 \text { (mean) } \\ 1 . \text { accredt }= & 0.3393665 \text { (mean) } \\ \text { Frmszculv= } & 1.904977 \text { (mean) }\end{array}$




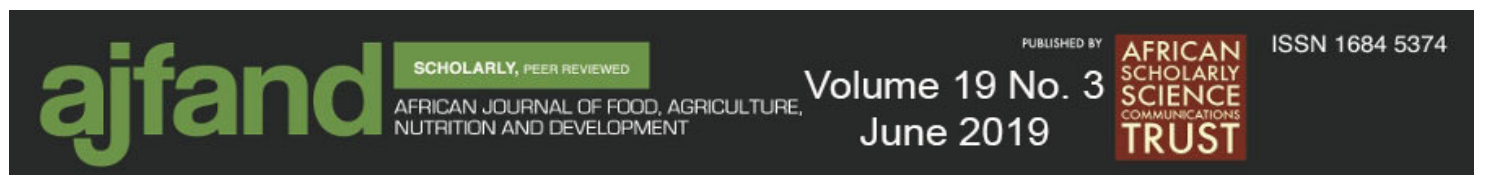

Table 3b: Marginal Effects at the means estimates of the Binary Probit Model

\begin{tabular}{l|cccc}
\hline SWC adoption decision & delta-method & & & \\
\hline Age & $\mathbf{d y} / \mathbf{d x}$ & $\mathbf{s t d}$. error & $\mathbf{z}$ & $\mathbf{p}>|\mathbf{z}|$ \\
1.gender & -0.0179 & 0.0034 & $-5.26^{*}$ & 0.000 \\
years of formal education & -0.4111 & 0.0549 & $-7.49^{*}$ & 0.000 \\
1.land-acquisition & -0.0243 & 0.0088 & $-2.75^{*}$ & 0.006 \\
1.access-to-credit & -0.0606 & 0.1047 & -0.58 & 0.563 \\
farm size cultivated & -0.0454 & 0.0833 & -0.55 & 0.583 \\
\hline
\end{tabular}

Note: $d y / d x$ for factor levels is the discrete change from the base level $* p<0.01 ; * * * p<0.1$ level, respectively

Source: Data analysis, 2017

\section{goodness-of-fittest 1}

number of observations $=221$

number of covariate patterns $=208$

Pearson $\operatorname{chi}^{2}(201)=188.90$

Prob $>\mathrm{chi}^{2}=0.7198$

goodness-of-fit test 2

Table 3c: Quantiles of estimated probabilities

\begin{tabular}{|l|l|l|l|l|l|l|}
\hline Group & Prob & Obs_1 & Exp_1 & Obs_0 & Exp_0 & Total \\
\hline 1 & 0.2371 & 8 & 3.9 & 15 & 19.1 & 23 \\
2 & 0.3325 & 4 & 6.3 & 18 & 15.7 & 22 \\
3 & 0.4155 & 8 & 8.2 & 14 & 13.8 & 22 \\
4 & 0.5125 & 9 & 10.4 & 13 & 11.6 & 22 \\
5 & 0.5875 & 10 & 12.1 & 12 & 9.9 & 22 \\
\hline 6 & 0.6602 & 16 & 13.7 & 6 & 8.3 & 22 \\
7 & 0.7630 & 11 & 15.5 & 11 & 6.5 & 22 \\
8 & 0.8627 & 20 & 17.9 & 2 & 4.1 & 22 \\
9 & 0.9521 & 21 & 20.2 & 1 & 1.8 & 22 \\
10 & 0.9997 & 22 & 21.6 & 0 & 0.4 & 22 \\
\hline
\end{tabular}

Number of observations $=221$, number of groups $=10$, Hosmer-Lemeshow $\operatorname{chi}^{2}(8)=15.08$, Prob $>$ chi $^{2}=0.0576$

Source: Data analysis, 2017 


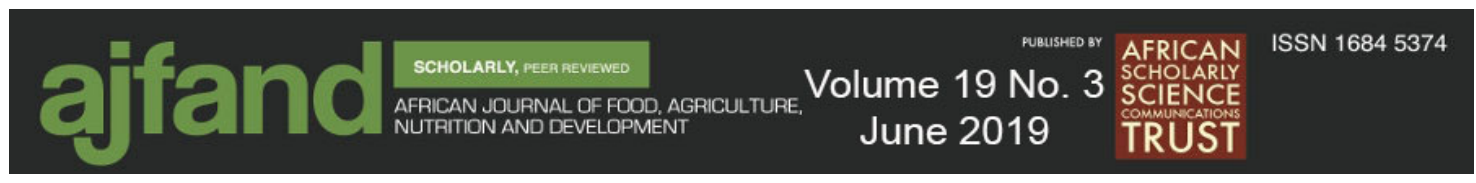

Table 4a: Poisson Regression Estimates

\begin{tabular}{|c|c|c|c|c|}
\hline $\begin{array}{l}\text { Number of } \text { SWC } \\
\text { practices adopted }\end{array}$ & Coefficient & std. error & $\mathbf{z}$ & $\mathbf{p}>|\mathbf{z}|$ \\
\hline Age & -0.0241 & 0.0053 & $-4.54^{*}$ & 0.000 \\
\hline 1.gender & -0.6571 & 0.1471 & $-4.47^{*}$ & 0.000 \\
\hline years of formal education & -0.0266 & 0.0191 & -1.39 & 0.164 \\
\hline 1.land-acquisition & 0.0143 & 0.1917 & 0.07 & 0.940 \\
\hline 1.access-to-credit & 0.3239 & 0.1516 & $2.14^{* *}$ & 0.033 \\
\hline farm size cultivated & 0.1890 & 0.0572 & $3.30^{*}$ & 0.001 \\
\hline constant & 1.4881 & 0.3650 & $4.08^{*}$ & 0.000 \\
\hline
\end{tabular}

Number of observations $=221, \log$ likelihood $=-314.97206$

LR chi $^{2}(6)=52.70$, Prob $>$ chi $^{2}=0.0000$, Pseudo $\mathrm{R}^{2}=0.0772$

${ }^{*} p<0.01 ; * * p<0.05$ level, respectively

Source: Data analysis, 2017

\section{goodness-of-fit test}

Deviance goodness-of-fit $\quad=372.1005$

Prob $>$ chi $^{2}(214) \quad=0.0000$

Pearson goodness-of-fit $\quad=345.9527$

Prob $>\operatorname{chi}^{2}(214) \quad=0.0000$

Table 4b: Negative Binomial Regression Estimates

\begin{tabular}{|c|c|c|c|c|}
\hline $\begin{array}{l}\text { Number of SWC } \\
\text { practices adopted }\end{array}$ & coefficient & std. error & $\mathbf{z}$ & $\mathbf{p}>|\mathbf{z}|$ \\
\hline Age & -0.0272 & 0.0083 & $-3.27^{*}$ & 0.001 \\
\hline 1.gender & -0.7240 & 0.2337 & $-3.10^{*}$ & 0.002 \\
\hline years of formal education & -0.0233 & 0.0270 & -0.86 & 0.338 \\
\hline 1.land-acquisition & 0.0171 & 0.2811 & 0.06 & 0.951 \\
\hline 1.access-to-credit & 0.3163 & 0.2234 & 1.42 & 0.157 \\
\hline farm size cultivated & 0.2216 & 0.0915 & $2.42^{* *}$ & 0.016 \\
\hline constant & 1.6126 & 0.5883 & $2.74^{*}$ & 0.006 \\
\hline /lnalpha & -0.0419 & 0.2837 & & \\
\hline alpha & 0.9589 & 0.2720 & & \\
\hline
\end{tabular}

Likelihood-ratio test of alpha $=0$ : $\operatorname{chibar}^{2}(01)=30.81$, Prob $>=\operatorname{chibar}^{2}=0.000$

Number of observations $=221, \log$ likelihood $=-229.56948$, Dispersion $=$ mean

Prob $>$ chi $^{2}=0.0000$, Pseudo $\mathrm{R}^{2}=0.0400, \mathrm{LR}_{\mathrm{chi}}{ }^{2}(6)=24.99$

${ }^{*} p<0.01 ; * * * p<0.05$ level, respectively

Source: Data analysis, 2017 


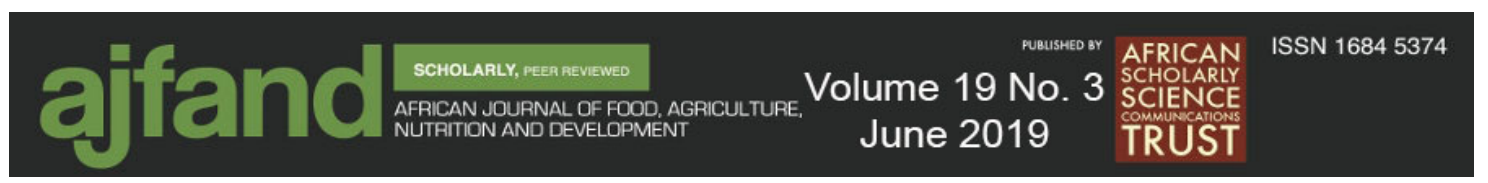

Table 4c: Incidence rate ratio of the Negative Binomial Regression Model

\begin{tabular}{l|cccc}
\hline $\begin{array}{l}\text { Count of SWC practices } \\
\text { adopted }\end{array}$ & IRR & std. error & $\mathbf{z}$ & $\mathbf{p}>|\mathbf{z}|$ \\
\hline Age & 0.9730 & 0.0081 & $-3.27^{*}$ & 0.001 \\
1.gender & 0.4847 & 0.1133 & $-3.10^{*}$ & 0.002 \\
years of formal education & 0.9769 & 0.0264 & -0.86 & 0.338 \\
1.land-acquisition & 1.0173 & 0.2860 & 0.06 & 0.951 \\
1.access-to-credit & 1.3721 & 0.3065 & 1.42 & 0.157 \\
farm size cultivated & 1.2480 & 0.1142 & $2.42^{* *}$ & 0.016 \\
constant & 5.0161 & 2.9513 & $2.74^{*}$ & 0.006 \\
\hline /lnalpha & -0.0419 & 0.2837 & & \\
\hline alpha & 0.9589 & 0.2720 & & \\
\hline
\end{tabular}

Likelihood-ratio test of alpha $=0$ : $\operatorname{chibar}^{2}(01)=30.81, \operatorname{Prob}>=\operatorname{chibar}^{2}=0.000$

Number of observations $=221, \log$ likelihood $=-229.56948$, Dispersion $=$ mean

Prob $>$ chi $^{2}=0.0000$, Pseudo $\mathrm{R}^{2}=0.0400, \mathrm{LR}_{\mathrm{chi}}{ }^{2}(6)=24.99$

${ }^{*} p<0.01 ;{ }^{* *} p<0.05$ level, respectively

Source: Data analysis, 2017 


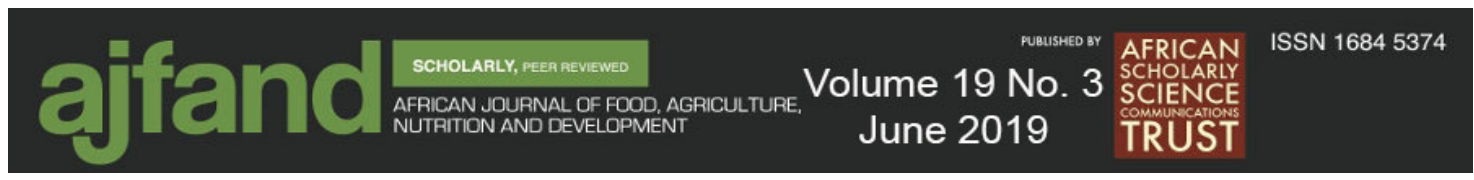

\section{REFERENCES}

1. Ezeaku PI Soil conservation and management options for adaptation to climate change in the 21 st century In: Enete, A.I. and Uguru, M.I. (eds). Critical Issues in Agricultural Adaptation to Climate Change in Nigeria, Enugu, Chengo Limited, 2012; 84-113.

2. Dumanski J, Peiretti J, Benitis R, McGary D and C Pieri The Paradigm of Conservation Tillage. Proceedings of World Association of Soil and Water Conservation, 2006; 58-64.

3. Nyangena W Social Networks in Sustainable Agriculture. In: UN Expert Group Meeting on 'Sustainable Land Management and Agricultural Practices in Africa, bridging the gap between Research and Farmers'. Organized in University of Gothenburg, Sweden April 16-17, 2009.

4. Egbetokun OA, Omonona BT and AS Adedeji Effects of Land Degradation on Maize-based Farm Resource Productivity in Oyo state, Nigeria. Direct Research Journal of Agriculture and Food Science (DRJAFS), 2014; 2(1): 8-12.

5. Ajayi AS Land Degradation and the Sustainability of Agricultural Production in Nigeria: A Journal of Soil Science and Environmental Management, 2015; 6(9): 234-240.

6. Oyakhilomen $\mathbf{O}$ and RG Zibah Agricultural Production and Economic Growth in Nigeria: Implication for Rural Poverty Alleviation. Quarterly Journal of International Agriculture, 2014; 53(3): 207-223.

7. World Conference on Environment and Development (WCED) 'Our Common Future', Oxford University Press, New York, 1987.

8. Long JS and J Freese Regression models for categorical dependent variables using STATA. (3rd edition ed.) College Station, TX: US: Stata Press, 2014.

9. Williams R Marginal Effects for Continuous Variables. University of Notre Dame. Revised version, January 20, 2018. https:/www3.nd.edu/ rwilliam/

10. Nagler J Interpreting probit analysis, New York University, 1994.

11. Sebopetji TO and A Belete An application of Probit analysis to factors affecting small-scale farmers' decision to take credit: a case study of the Greater Letaba Local Municipality in South Africa. African Journal of Agricultural Research, 2009; 4(8): 718-723.

12. Baum CF Models for Count Data and Categorical Response Data. Boston College and DIW Berlin, 2010. 


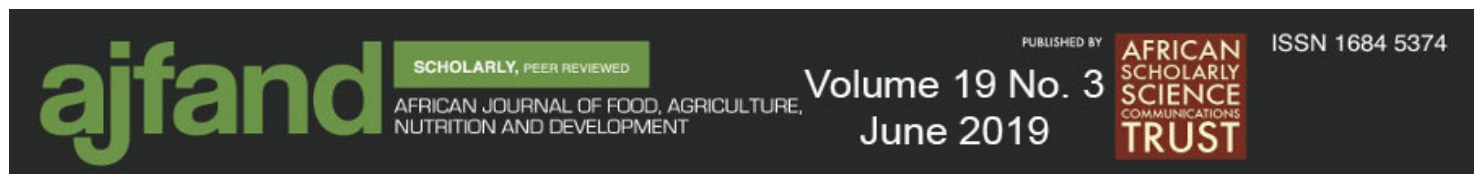

13. Olufunmilayo OL, Bamire SA and AS Ogunleye Factors Influencing Levels and Intensity of Adoption of New Rice for Africa (NERICA) Among Rice Farmers in Ogun State, Nigeria. International Journal of Agricultural Economics, 2017; 2(3): 84-89.

14. Awoyinka YA and JA Akinwumi Effects of Livelihood Strategies on Adoption of Farm-specific Land Management Practices among Crop Farmers in South-West, Nigeria. Research Journal of Agriculture and Biological Sciences, 2010; 6(6): 763772.

15. Hosmer DW Jr, Lemeshow SA and RX Sturdivant Applied Logistic Regression. 3rd ed. Hoboken, NJ: Wiley, 2013.

16. Piza EL Using Poisson and Negative Binomial Regression Models to Measure the Influence of Risk on Crime Incident Counts. Rutgers Center on Public Security. Newark, NJ, USA, 2012.

17. Pedzisa T, Rugube $\mathbf{L}$, Winter-Nelson A, Baylis $\mathbf{K}$ and $\mathbf{K}$ Mazvimavi The Intensity of adoption of Conservation agriculture by smallholder farmers in Zimbabwe. Agrekon, 2015; 54(3): 1-22.

18. Cameron AC and PK Trivedi Regression Analysis of Count Data.2nd ed. New York: Cambridge University Press, 2013. 